\title{
Analysis of Rainfall Factors and Soil Erosion in Different Soil and Water Conservation Measures in the Karst Plateau-Mountain
}

\author{
Long Yuan ${ }^{1}$, Kunqian Yue ${ }^{2}$, Zaike $\mathrm{Gu}^{2}$, Hu Chen ${ }^{1}$, Yongkuan $\mathrm{Chi}^{1 *}$ \\ ${ }^{1}$ Guizhou Normal University/ State Engineering Technology Institute for Karst Desertification Control, \\ Guiyang 550001, China \\ ${ }^{2}$ Guizhou Provincial Monitoring Station of Soil and Water Conservation, Guiyang 550002, China
}

Received: 28 February 2021

Accepted: 15 April 2021

\begin{abstract}
The fragile ecological environment and serious soil erosion in the karst rocky desertification area, which have become important factors restricting the development of agricultural economy. This paper analyzed the rainfall factors and soil loss of different soil and water conservation measures by regularly observing different soil and water conservation measures in the runoff plot of the karst plateaumountain. The results showed that: 1) The use of multiple spatial structures of the land had a significant effect on preventing and controlling soil erosion by comparative analysis of different soil and water conservation measures. 2) Reasonable planting mode had little effect on runoff producing of soil, and its corrosion resistance was ranked only second to soil conservation measures. Therefore, changing the way of human interference with nature and following the laws of nature will help to reduce the damage for the ecological environment. 3) By analyzing the relationship between rainfall, average rainfall intensity, rainfall erosivity and sediment content, rainfall intensity had no significant effect on soil loss, rainfall intensity was one of the factors that produce soil erosion. The relationship between average rainfall intensity and sediment content in water conservation forest was $\mathrm{R}^{2}=0.95$, the linear fitting formula was $\mathrm{y}=0.2771 \mathrm{x}+3.4629$. The average rainfall intensity of corn and broad beans (high-groove planting) and the sediment content were Pearson's significant correlation $\left(\mathrm{R}^{2}=0.91\right)$, the linear fitting formula was $y=0.7685 x-3.839$. The sediment content varies with the average rain intensity, and the correlation was significant. Rainfall intensity was an important factor of soil erosion, while rainfall erosion was one of the key factors in soil sediment production.
\end{abstract}

Keywords: karst, rocky desertification, soil and water conservation measures, rainfall, soil erosion

*e-mail: hebeichiyongkuan@163.com 


\section{Introduction}

The karst rocky desertification in southern China is one of the main ecological and environmental problems in China. Based on the fragile ecological environment, coupled with man-made interference, soil productivity is degraded, surface bedrock is exposed, and available land resources are continuously reduced, which have an important impact on agricultural production. Fang Qian [1] used artificial rainfall experiments to study the characteristics of soil erosion on slopes with different agricultural farming measures under different rainfall intensities. Fang Rongjie [2] analyzed the characteristics of runoff and sediment yield in karst sloping farmland by artificially simulating rainfall conditions, Qi Zhijuan and other people [3] studied the effects of different measures on soil erosion, and it was concluded that the characteristics of runoff and sediment yield and water infiltration on slopes were closely related to farming measures, the effects of different farming measures on water storage and sediment reduction were as follows: cross-slope planting $>$ ridge-oriented field $>$ free farming $>$ conventional farming $>$ bare land. Liu Shirong and other studies [4] showed that depending on the type of forest and its canopy closure, precipitation, and precipitation intensity, the canopy can intercept $12 \%$ to $35 \%$ of the total precipitation. Xiao Peiqing [5] used artificial rainfall experiments to quantitatively study the flow and sediment reduction effects of shrubs on a $20^{\circ}$ steep slope under different rainfall intensities. Ji Qifang [6] analyzed the flow and sediment reduction of vegetation in Guizhou karst areas, and the overall performance was economic forest $>$ artificial grassland $>$ water conservation forest. Li Xiang [7] studied the effects of different soil and water conservation measures on the physical properties of slope farmland in red soil. However, there are currently few studies on soil erosion by adopting water and soil conservation measures for different spatial structures. In this study, we used the method of field observation to set up standard runoff plots in the Longguidi small watershed of Liupanshui City, Guizhou Province, and conducted regular observations to analyze the sand reduction benefits and the factors affecting soil loss of different soil and water conservation measures and different spatial structures in the karst plateaumountain, which was to provide reference suggestions for soil erosion prevention and control.

\section{Materials and Methods}

\section{Overview of the Study Area}

The monitoring site for soil and water conservation in Longguidi of Liupanshui City, Guizhou Province is built next to Longguidi Reservoir, located in the Dewu Sub-district Office of Zhongshan District, where geographic location is $104^{\circ} 46^{\prime} 02^{\prime \prime}-104^{\circ} 46^{\prime} 08^{\prime \prime} \mathrm{E}$ and $26^{\circ} 36^{\prime} 40^{\prime \prime}-26^{\circ} 36^{\prime} 45^{\prime \prime} \mathrm{N}$. The annual rainfall is $1200.4 \mathrm{~mm}$, the annual temperature is $15^{\circ} \mathrm{C}$, the terrain is high in the northwest and low in the southeast, with an altitude of 1830-2310 $\mathrm{m}$. The carbonate rock formations in the small watershed are widely published, and due to structural influences, the rocks are broken and groundwater is abundant. Most of the small watershed presents a karst landscape, with dissolution depressions, undercurrents, karst spring wells, and peak clusters. The soil types mainly include yellow loam, mountain yellow brown loam, and it belongs to the northern subtropical monsoon humid climate area. Influenced by high latitude, warm in winter and cool in summer, the climate is pleasant. The average annual temperature is 13 to $14^{\circ} \mathrm{C}$, the average temperature in January is 3 to $6.3^{\circ} \mathrm{C}$, the average temperature in July is 19.8 to $22^{\circ} \mathrm{C}$, the annual sunshine hours are between 1253-1556 hours, the annual precipitation is 1200 to $1500 \mathrm{~mm}$, and the frost-free period is 200 to 300 days, the climate difference in some areas is obvious because of the large terrain undulations (Table 1).

\section{Test Design}

Different soil and water conservation measures were set up in the runoff plot of soil and water conservation monitoring points in Longguidi, Liupanshui City, Guizhou Province, including Cupressus duclouxiana+ wormwood, Trifolium, Lolium perenne, Cryptomeria fortune ${ }^{+}$wormwood, Trifolium, Lolium perenne, corn, broad beans (high-groove planting), corn, broad beans (farming downhill) and control plots. The relationship between rainfall, average rain intensity and soil loss was observed. The horizontal projection area of each runoff plot was $100 \mathrm{~m}^{2}$, the rectangle with a horizontal projection length of $20 \mathrm{~m}$ and a width of $5 \mathrm{~m}$, it was designed the cement mortar 1:3 ratio that was used to wipe the surface to prevent rain water from flowing into the plot. The bottom of the plot was provided with a collecting tank, which was convenient for runoff to be injected from the collecting port into the lower collecting ground.

\section{Determination Method}

A water guide pipe was installed at the collecting port of each slope. After the rain was produced, the water sample was stirred, then we can sample, the sample was placed for $24 \mathrm{~h}$ to precipitate, then dried, and weighed with an electronic scale.

\section{Data Acquisition and Processing}

The data are derived from the successive monitoring data of soil and water conservation monitoring stations in 2017, including runoff sediment, average rain intensity, soil loss, rainfall, sediment content, etc. rainfall was derived from HOBO-U30 automatic weather station and wireless self-recording rainfall meter; sand content was used manual sampling, oven, 


\begin{tabular}{|c|c|c|c|c|c|}
\hline 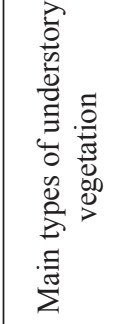 & 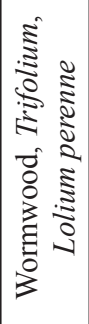 & 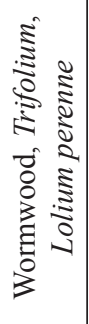 & - & - & - \\
\hline 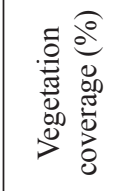 & $\ddot{\infty}$ & f & $\nabla$ & 0 & 0 \\
\hline 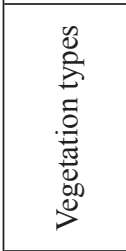 & 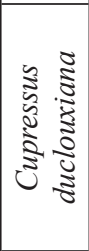 & 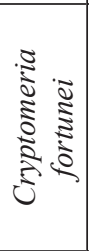 & 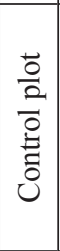 & 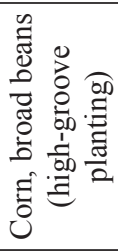 & 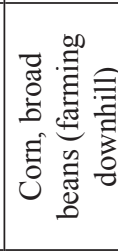 \\
\hline 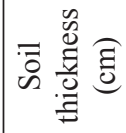 & in & in & in & in & in \\
\hline 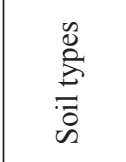 & $\begin{array}{l}\overline{0} \\
0 \\
z \\
0 \\
0 \\
\overline{0}\end{array}$ & $\begin{array}{l}\overline{0} \\
\infty \\
z \\
0 \\
0 \\
\overline{0}\end{array}$ & $\begin{array}{l}\overline{0} \\
0 \\
z \\
0 \\
\overline{0} \\
\bar{z}\end{array}$ & $\begin{array}{l}\overline{0} \\
0 \\
3 \\
0 \\
0 \\
0\end{array}$ & $\begin{array}{l}\overline{0} \\
0 \\
\text { zo } \\
0 \\
0 \\
0\end{array}$ \\
\hline $\begin{array}{l}0 \\
0 \\
0 \\
0 \\
0 \\
0 \\
0 \\
0 \\
0\end{array}$ & 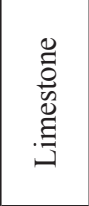 & 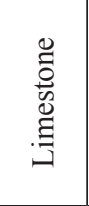 & 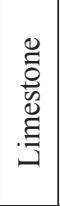 & 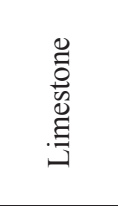 & 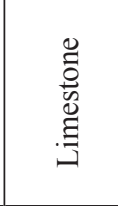 \\
\hline 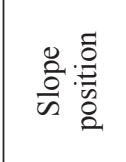 & $\begin{array}{l}0 \\
\frac{0}{0} \\
\frac{0}{0} \\
0 \\
\infty \\
\sum\end{array}$ & 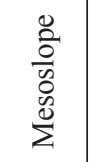 & $\begin{array}{l}\frac{0}{0} \\
\frac{0}{0} \\
\frac{0}{0} \\
0 \\
\sum_{i}^{0}\end{array}$ & $\begin{array}{l}\frac{0}{0} \\
\frac{0}{0} \\
0 \\
\sum_{0}^{0} \\
\Sigma\end{array}$ & $\begin{array}{l}0 \\
\frac{0}{0} \\
\frac{0}{0} \\
0 \\
0 \\
0^{0}\end{array}$ \\
\hline 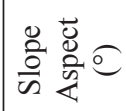 & สิ & $\underset{\sim}{\sim}$ & $\stackrel{\sim}{\sim}$ & $\stackrel{\sim}{\sim}$ & สิ \\
\hline$\frac{0}{\omega} \cdot \frac{\overrightarrow{0}}{\tilde{0}}$ & $\approx$ & $\approx$ & $\ddot{\imath}$ & $\approx$ & $\ddot{\sim}$ \\
\hline 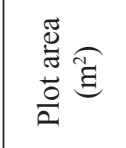 & 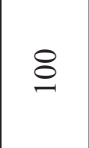 & 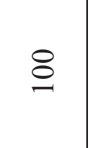 & 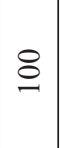 & 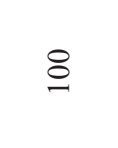 & 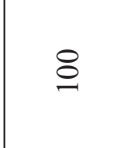 \\
\hline 焉 & in & in & in & in & in \\
\hline 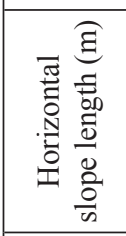 & 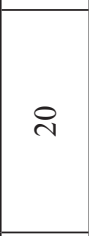 & 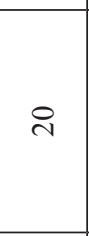 & $\stackrel{\sim}{\sim}$ & $\stackrel{\sim}{\sim}$ & ㄱ. \\
\hline 흥 & - & $\sim$ & $n$ & $\sigma$ & $n$ \\
\hline
\end{tabular}

electronic analytical balance and ordinary electronic scale to determine.

\section{Results and Analysis}

\section{Comparative Analysis of Soil Loss in Different Soil Conservation Measures}

The core of comprehensive control of rocky desertification was ecological restoration, afforestation, returning farmland to forest (grass) and other control methods [8], soil erosion changes were analyzed in different crop planting patterns and forest-grass compound planting patterns, the soil and water conservation effects were as follows: water conservation forest $>$ corn, broad bean (high-groove planting) $>$ control plot $>$ corn and broad bean (farming downhill). The overall effect of reducing soil loss by compound planting of Cupressus duclouxiana+ wormwood and Cryptomeria fortunei+wormwood was the same, soil loss was reduced by $42.70 \%$ to $97.92 \%$ compared with the control plot. The soil loss of mixed planting in water conservation forest decreased to $97.92 \%$, the soil loss of corn and broad bean (high-groove planting) decreased to $42.70 \%$, and the soil loss rate of corn and broad bean (farming downhill) increased $480.72 \%$. The soil loss of corn and broad beans through the downhill tillage method was the most serious, while the soil loss was the least in the model of combined planting of grass by water conservation forest. Because of the small interference, scattered vegetation cover, the soil in the control plot was easy to form, the soil loss was slightly less than that of corn (farming downhill), and the corrosion resistance of corn (high-groove planting) was significantly enhanced. Therefore, reasonable land use can reduce soil loss and reach a balance between land use and human interference (Table 2).

\section{Changes of Rainfall and Soil Loss in Different Months}

As we can see from Fig. 1 to Fig. 4, there was no soil loss in runoff plot of the control plot, corn, broad bean (high-groove), soil and water conservation forest in January and February, and soil loss was gradually affected by rainfall in March. The amount of rainfall gradually increased in April, and the amount of soil loss increased first, then decreased, and finally the amount of soil loss gradually increased which was affected by the amount of rainfall increased and, and it was reached a peak in September. The amount of soil loss generally changed with the amount of rainfall, and some showed the opposite trend. Before the flood season, the amount of rainfall was generally small, and the soil loss was less affected by the rainfall. After entering the flood season, the rainfall gradually increased, and the amount of soil loss gradually increased. Although there was rainfall after September, there was no soil runoff, so it 
Table 2. Comparative analysis of soil loss of different vegetation types.

\begin{tabular}{|c|c|c|}
\hline Landform & Vegetation types & Soil loss $\left(\mathrm{t} / \mathrm{hm}^{2}\right)$ \\
\hline Karst plateau-mountain & Cupressus duclouxiana+ Wormwood, Trifolium, Lolium perenne & 0.0004 \\
\hline Karst plateau-mountain & Cryptomeria fortunei+ Wormwood, Trifolium, Lolium perenne & 0.0004 \\
\hline Karst plateau-mountain & Control plot & 0.0192 \\
\hline Karst plateau-mountain & Corn, broad beans (high-groove planting) & 0.0110 \\
\hline Karst plateau-mountain & Corn, broad beans (farming downhill) & 0.1115 \\
\hline
\end{tabular}

has not been recorded. The magnitude of rainfall cannot directly determine the generation of runoff, large rainfall does not mean that runoff will be generated. The generation of runoff was not only affected by precipitation and evaporation, but also affected by underlayment, in terms of vegetation, soil, human activities and so on, rainfall was one of the factors that cause soil loss. Under the same rainfall conditions, the soil loss in the control plot was 46.63 times, 6.17 times and 0.30 times that of soil and water

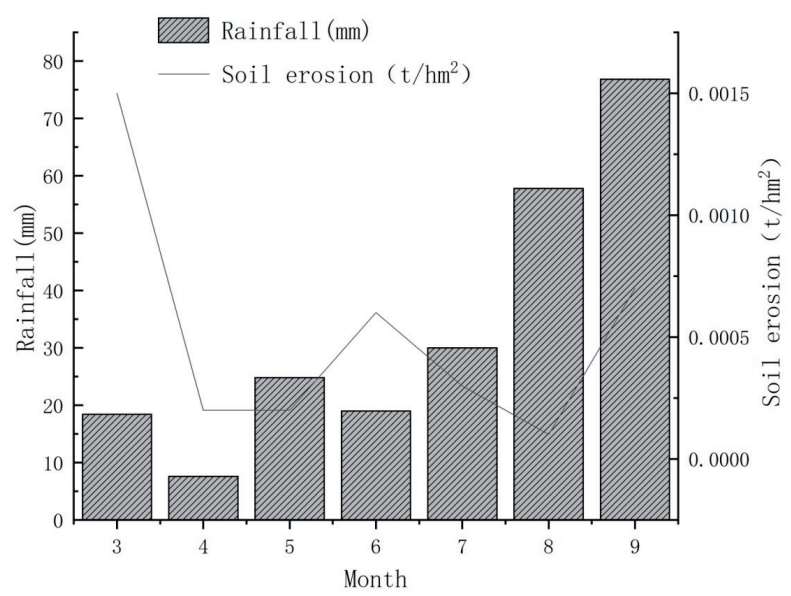

Fig. 1. Changes of rainfall and soil loss in corn and broad bean (farming downhill).

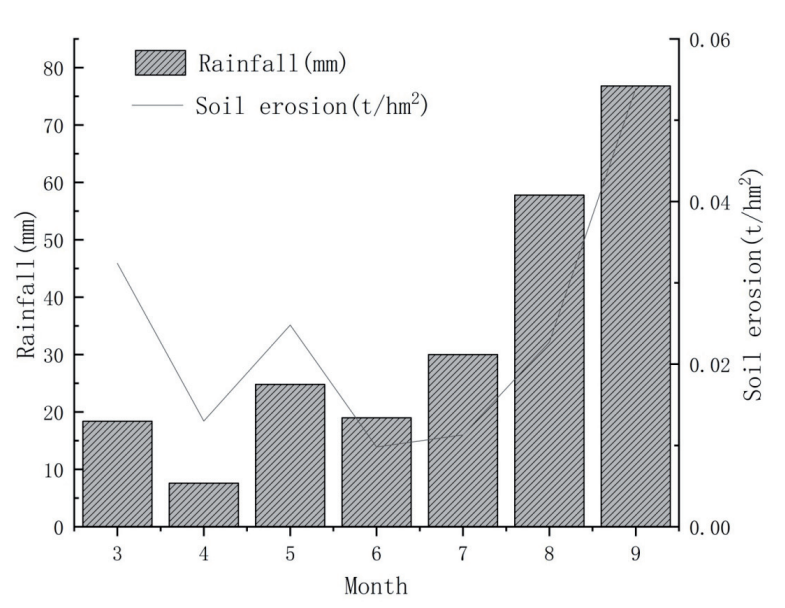

Fig. 2. Changes of rainfall and soil loss in the control plot. conservation forests, corn, broad beans (high-groove planting), corn and broad beans (farming downhill).

\section{Changes of Average Rainfall Intensity and Soil Loss in Different Measures}

Through monitoring of the average rainfall intensity and sediment content in runoff plots of different soil and water conservation measures, the sediment content

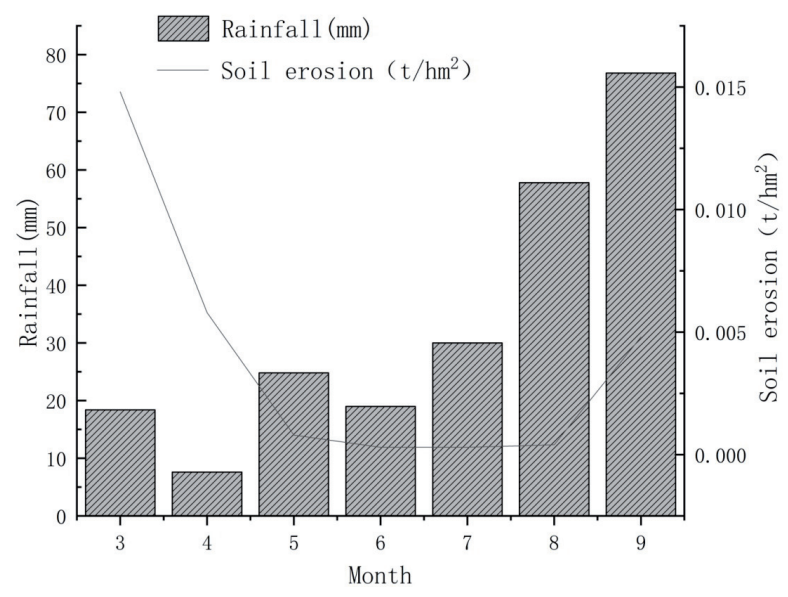

Fig. 3. Changes of rainfall and soil loss in corn and broad bean (high-groove planting).

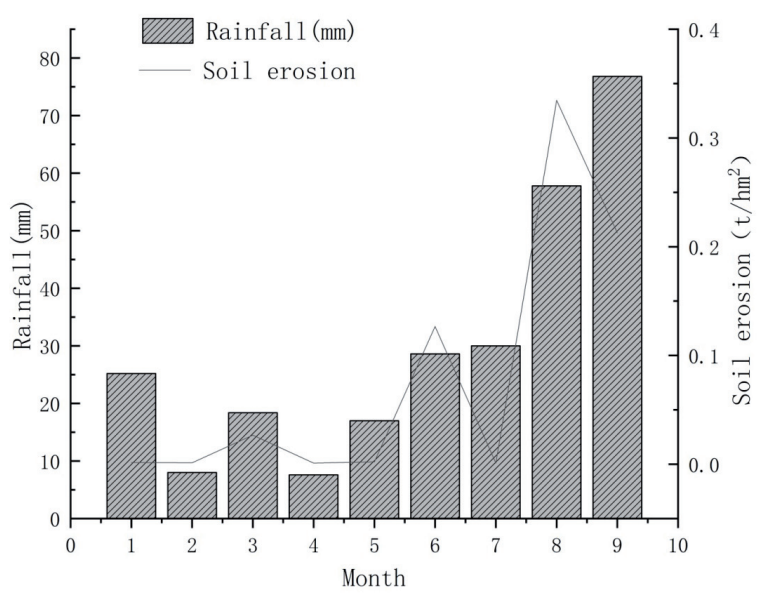

Fig. 4. Changes of rainfall and soil loss in water conservation forest. 
Table 3. Correlation analysis of rainfall factors.

\begin{tabular}{|c|c|c|c|c|c|c|}
\hline Variable & Rainfall & $\begin{array}{c}\text { Average rainfall } \\
\text { intensity }\end{array}$ & $\begin{array}{c}\text { Maximum 30 } \\
\text { minutes rainfall }\end{array}$ & Rainfall erosion & $\begin{array}{c}\text { Soil } \\
\text { loss }\end{array}$ & $\begin{array}{c}\text { Sediment } \\
\text { content }\end{array}$ \\
\hline Average rainfall intensity & $0.86^{* *}$ & & & & & \\
\hline Maximum 30 minutes rainfall & $0.86^{* *}$ & $0.87^{* *}$ & & & & \\
\hline Rainfall erosion & $0.93^{* *}$ & $0.93^{* *}$ & $0.89^{* *}$ & & & \\
\hline Soil loss & $0.85^{* *}$ & $0.85^{* *}$ & $0.85^{* *}$ & $0.97^{* *}$ & & \\
\hline Sediment content & $0.85^{* *}$ & $0.85^{* *}$ & $0.89^{* *}$ & $0.93^{* *}$ & $0.95^{* *}$ & \\
\hline
\end{tabular}

Note: ** means a significant positive correlation at the level of $P<0.01$

changes with the change of the average rainfall intensity, this conclusion was consistent with Nie Xiaodong's research [9]. The sediment content was more obviously affected by the rainfall intensity, it showed that rainfall has eroded the soil within a certain period of time, and the erosion intensity had exceeded the erosion resistance of the soil, thereby increased the sand content. The average rainfall intensity of corn and broad beans (high-groove planting) and the sediment content were Pearson's significant correlation $\left(\mathrm{R}^{2}=0.91\right)$, the linear fitting formula was $y=0.7685 x-3.839$. The relationship between average rainfall intensity and sediment content in corn and broad beans (farming downhill) was $\mathrm{R}^{2}=0.54$, the relationship between average rainfall intensity and sediment content in water conservation forest was $\mathrm{R}^{2}=0.95$, the linear fitting formula was $\mathrm{y}=0.2771 \mathrm{x}+3.4629$. This showed that among the rainfall factors, the average rainfall intensity was the key factor for runoff generation and the dynamic condition for soil splash erosion.

The runoff plots of the control, corn and broad beans (farming downhill) were greatly affected by the average rainfall intensity, followed by corn and broad beans (high-groove planting). Under the total average

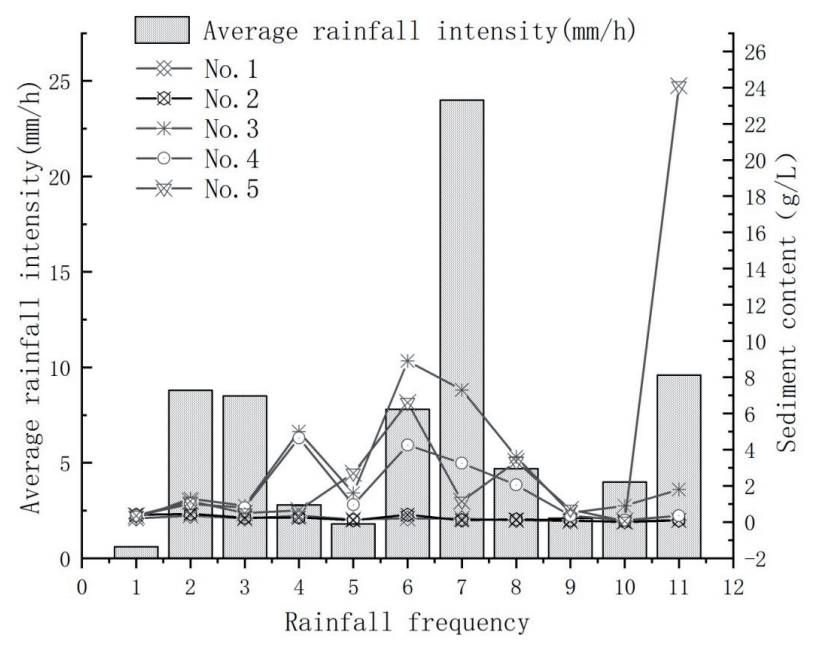

Fig. 5. Relationship between average rainfall intensity and soil loss of different soil and water conservation measures. rainfall intensity, the overall sediment reduction rate was $43.43 \% \sim 93.90 \%$ compared with the control plot, the sand reduction rate of Cupressus duclouxiana was $93.90 \%$, the sand reduction rate of Cryptomeria fortunei was $92.81 \%$, the sand reduction rate of corn and broad bean (high-groove planting) is $43.43 \%$, while that of corn and broad bean (farming downhill) increased the sand content by $29 \%$ (Fig. 5).

\section{Correlation Analysis of Rainfall Factors and Soil Loss}

Studies believed that rainfall was the main environmental factor that determines the amount of runoff and sediment on the surface [10], using spss18.0 to analyze the correlation between rainfall factors and soil loss, rainfall and average rainfall intensity, maximum 30-minute rainfall, rainfall erosivity, soil loss, and sand content were extremely significantly positively correlated $(P<0.01)$. The correlation coefficient was above 0.85 , and the average rainfall intensity had a very significant positive correlation with the maximum 30-minute rainfall, rainfall erosivity, soil loss, and sand content $(P<0.01)$. Rainfall was an important factor affecting soil loss, and rainfall erosivity was extremely positively correlated to the amount of soil loss and sediment content $\left(P<0.01, \mathrm{R}^{2}=0.97, \mathrm{R}^{2}=0.93\right)$, rainfall erosivity was the key factor of soil sediment production (Table 3).

\section{Discussion}

The amount of soil loss under the four soil and water conservation measures was lower than that of the control plot, different soil and water conservation measures will produce different amounts of erosion due to various differences in the underlying surface and the same rainfall [11]. The sediment content changes with the change of rainfall intensity, especially the comparison plots and crops cultivated downhill. As a result of soil and water conservation measures taken, the surface spatial structure has been changed to avoid direct erosion of the ground by rainfall. During rainfall, the surface vegetation intercepts rainfall, 
buffers the rainfall intensity, causes the rainfall to fall twice, alleviates the impact of rainfall, and redistributes the surface runoff in the rainfall process, effectively alleviates runoff formation, reduces soil sediment content and achieves soil and water conservation [12]. The 4 kinds of soil and water conservation measures in this study had some effect, but the effect of corn and broad bean (farming downhill) was not ideal. The overall effect of soil and water conservation was as follows: water conservation forest model $>$ corn, broad bean (high-groove planting) $>$ control plot $>$ corn, broad bean (farming downhill). The soil sediment retention rate of the four kinds of soil conservation measures increased by $42.70 \% \sim 97.92 \%$ compared with that of the control plot. The soil and water conservation forest plots are planted with Cupressus duclouxiana and Cryptomeria fortunei respectively, wormwood, clover, and ryegrass were planted under the forest, which was less subject to human disturbance. It made full use of the multiple spaces of the land to increase the coverage of vegetation, and the root system of the plant was resistant to erosion of the improved soil [13]. Grasses have well-developed root systems, good water retention and soil consolidation effects [14-15]. Corn and broad beans were adopted different planting methods, their soil and water conservation effects were significantly different, the use of high-groove planting soils increased the soil sediment retention rate by $42.70 \%$, while the use of downhill farming had a higher soil loss rate than the control plot. On the one hand, a reasonable planting method can not only increase the soil retention rate but also ease the conflict between people and land. On the other hand, in the process of downhill farming, soil plowing and weeding can disturb the soil. In addition, downhill farming conformed to the direction of soil loss, it resulted in a substantial increase in soil loss. This study selected fewer varieties, mainly in terms of soil and water conservation forests and crops. The single plant variety cannot provide more references for plant selection in karst rocky desertification areas. Therefore, we will strengthen multiple varieties in future research. The experimental research of the karst rocky desertification area can not only improve the benefits of water and soil conservation but also increase the economic benefits, and provide suggestions for alleviating the contradiction between human and land and regional economic development in karst rocky desertification areas.

\section{Conclusion}

(1) In karst rocky desertification areas, the ecological environment is fragile, the soil layer is shallow and the available land resources are limited. The changes of soil erosion were analyzed in different planting patterns of crops and forest-grass compound planting. The soil erosion effect was as follows: water conservation forest pattern $>$ corn, broad bean(high-groove planting)
$>$ control plot $>$ corn, broad bean (farming downhill), Dianbai compound planting grass and willow compound planting grass is the same, compared with control plot, soil loss was reduced by $42.70 \% \sim 97$. In this paper, soil and water conservation measures were adopted by using the multi-space structure of soil and water conservation. The overall effect of reducing soil loss by compound planting of Cupressus duclouxiana+wormwood and Cryptomeria fortune + +wormwood was the same, soil loss was reduced by $42.70 \%$ to $97.92 \%$ compared with the control plot. Analyzing different planting methods of crops and planting patterns of different composite soil and water conservation forests, using the multiple spatial structure of the land to take water and soil conservation measures, which has a significant effect on the prevention and control of soil erosion, and it can reach the level of almost no soil erosion.

(2) Comparative analysis of different planting methods of crops has shown that reasonable planting methods have a significant effect on reducing soil loss. The crops were planted with high-grooves farming, and their anti-erodibility was rank only second to water and forest protection measures. Compared with the control plot, the sand reduction rate of other soil and water conservation measures is $43.43 \% \sim 93.90 \%$, while the sediment content of crops cultivated downhill increases by $29 \%$. Therefore, it changes the way humans interfere with nature and follows the laws of nature, which helps to reduce destroy the ecological environment.

(3) By analyzing the relationship between average rainfall intensity and sediment content, the relationship between average rainfall intensity and sediment content in water conservation forest was $\mathrm{R}^{2}=0.95$, the linear fitting formula was $\mathrm{y}=0.2771 \mathrm{x}+3.4629$. The average rainfall intensity of corn and broad beans (high-groove planting) and the sediment content were Pearson's significant correlation $\left(\mathrm{R}^{2}=0.91\right)$, the linear fitting formula was $y=0.7685 x-3.839$. The sediment content varies with the average rain intensity, and the correlation was significant. Rainfall intensity was an important factor of soil erosion, while rainfall erosivity had a very significant positive correlation with soil loss and sand content $\left(P<0.01, \mathrm{R}^{2}=0.97, \mathrm{R}^{2}=0.93\right)$, which is a key factor in soil sediment production.

\section{Conflict of Interest}

The authors declare no conflict of interest.

\section{Acknowledgements}

The work was supported by Project of National Key Research and Development Program of China in the $13^{\text {th }}$ Five-year Plan: (2016YFC0502601, 2016YFC0502607), Guizhou Provincial Science and Technology Foundation: (Qian Ke He Ji Chu[2020]1Y153), the Innovation Group Project of Education Department of Guizhou Province 
([2021]013), Doctoral research project was supported by Guizhou Normal University (GZNUD[2019]1).

\section{References}

1. FANG Q., ZHAO L.S, WU F.Q. Effect of rainfall intensity on soil and water conservation of tillage practices. Agricultural Research in the Arid Areas 37 (2), 215, 2019.

2. FANG R.J., ZHU X.F., JIANG B.W., MO H.T. Characteristics of Runoff and Sediment on Karst Slopes Under Experiment Conditions of Simulated Rainfall. Research of Soil and Water Conservation 25 (3), 11, 2018.

3. QI Z.J., ZHANG Z.X., YANG A.Z. Characteristics of soil erosion by water under different soil and water conservation measures on sloping farmland of black soils. Bulletin of Soil and Water Conservation 32 (1), 89, 2012.

4. LIU S.R. Laws of hydrological and ecological function of forest ecosystem.Beijing, China Forestry Publishing House, 17, 1996.

5. XIAO P.Q., YAO W.Y., WANG C.G. Experimental study of effect of shrubs on runoff and sediment reduction and its hydrodanamic mechanism. Journal of Sediment Research 5, 33, 2012.

6. JI Q.F. Effects of different vegetation on slopes in Guizhou karst area. Nanjing, Nanjing University, 1, 2013.

7. LI X., YANG H.F., WU X., ZHANG J.Q. Effects of different soil and water conservation measures on soil physical properties in red soil slope field. Journal of Southern Agriculture, 47 (10), 1677, 2016.

8. CHI Y.K., XIONG K.N., CHEN H., MIN X.Y., LIAO J.J., SHEN X.Y. Effect of Grazing to Copper Pollution Meadow on Copper Metabolism in Wumeng Semi-fine Wool Sheep. Polish Journal of Environmental Studies 28 (3), 1083, 2019.

9. NIE X.D., LI Z.W., WANG X.Y., SHEN W.P., ZHANG X., GUO W., MA W.M., WANG S.G. Effect of rainfall intensity on soil loss from slope farmland of red soil and organic carbon enrichment in sediment. Acta Pedologica Sinica 50 (5), 900, 2013.

10. CHI Y.K., XIONG K.N., XIAO H. CHEN H., SONG S.Z., SHEN X.Y. Study on the relationship between disposition models of forest and grass and soil properties in karst rocky desertification areas of Southwest China. Fresenius Environmental Bulletin 29 (7), 5424, 2019.

11. DONG Y.P., CHI Y.K., XIONG K.N. Does grass-covered soil system guarantee better water retention in Southwest China during winter-to-spring? the observing evidence from lab. Fresenius Environmental Bulletin 29 (5), 3622, 2020.

12. YU Y.H., CHI Y.K. Ecological Stoichiometric Characteristics of Soil at Different Depths in a Karst Plateau Mountain Area of China. Polish Journal of Environmental Studies 29 (1), 969, 2020.

13. CHI Y.K., ZHANG Z.Z., SONG C.J., XIONG K.N., SHEN X.Y. Effects of Fertilization on Physiological and Biochemical Parameters of Wumeng Sheep in China's Wumeng Prairie. Polish Journal of Environmental Studies 29 (1), 79, 2020.

14. LIANG J.Z. Runoff Changes on Slope with Different Vegetation Measures in Red Soil Region. Bulletin of Soil and Water Conservation 35 (6), 159, 2015.

15. FAN M.H., CAI G.Q., CUI M. Soil erosion developed with the vertical belts in the gentle hilly black soil regions in Northeast China. Transactions of the Chinese Society of Agricultural Engineering, 21 (6), 8, 2005. 